\title{
Gilbert Simondon y Jean Piaget: a propósito DEL ARGUMENTO DEL ISOMORFISMO ${ }^{1}$
}

\section{Gilbert Simondon and Jean Piaget: Purposely the Argument of Isomorphism}

\author{
IsABeLLA BuILES ROLDÁN ${ }^{2}$ \\ Universidad EAFIT
}

DOI: 10.17533/udea.rp.v10n1a08

Recibido: 2017-08-02 Aceptado: 2017-10-16

Para citar este artículo en APA: Builes, I. (2018). Gilbert Simondon y Jean Piaget: a propósito del argumento del isomorfismo. Revista de Psicología Universidad de Antioquia, 10 (1),

195-214. DOI: 10.17533/udea.rp.v10n1a08

Resumen: En el presente artículo analizamos el argumento del isomorfismo, propuesto principalmente por la teoría de la Gestalt en psicología, a la luz de algunos elementos de la teoría de la individuación del ser de Gilbert Simondon y de la epistemología genética de Jean Piaget. Tenemos en cuenta que la propuesta de Piaget es una de las bases teóricas para la individuación psíquica y transindividual simondoniana, y, con base en esto, se ponen en relación ambos autores, a propósito del argumento del isomorfismo entre los distintos niveles de la realidad: físico, químico, biológico, psicológico y psicosocial o transindividual.

Palabras clave: transducción, individuación, metaestabilidad, Gestalt, psicología genética.
Abstract: In this article we analyze the argument of isomorphism, proposed mainly by Gestalt theory in psychology, in light of some elements from Gilbert Simondon's theory of individuation and Jean Piaget's genetic epistemology. We take into account that Piaget is one of the theoretical basis for Simondon's psychic and transindividual individuation, and, according to this, we establish a relation between both authors, purposely the argument of isomorphism amongst different levels in reality: physical, chemical, biological, psychological and psychosocial or transindividual.

Keywords: transduction, individuation, metastability, Gestalt, genetic psychology.

1 El artículo deriva de la investigación de maestría titulada Aspectos lógicos del pensamiento intuitivo y sus implicaciones en la toma de decisiones, financiada por la Universidad EAFIT de Medellín.

2 Psicóloga. Magíster en Estudios Humanísticos, Universidad EAFIT. Correo electrónico: ibuiles@ eafit.edu.co; http://orcid.org/0000-0002-9282-2233 


\section{Introducción}

En el presente artículo se ponen en relación dos autores: Jean Piaget y Gilbert Simondon, a propósito del argumento del isomorfismo entre los distintos niveles de la realidad. Para ello, primero, se exponen algunos de los planteamientos de la teoría de Gilbert Simondon sobre la individuación, teniendo en cuenta que para él el ser está en devenir, lo que supone la existencia de una operación fundamental que permite las modificaciones de una estructura en los distintos niveles de la realidad, llamada transducción. Luego, presentamos algunos elementos de la epistemología genética de Jean Piaget, enfatizando en la importancia que le otorga el autor a la comprensión del conocimiento a partir de sus procesos genéticos, en la medida en que estos se dan por medio de la transformación constante de estructuras y funciones. Finalmente, explicamos el argumento del isomorfismo, desde la psicología de la Gestalt, y contrastamos las posturas de ambos autores frente a este, para concluir que ambos están de acuerdo en privilegiar el estudio de los procesos genéticos, más que las estructuras estáticas, además de compartir que hay operaciones y estructuras isomorfas en los distintos niveles de la realidad.

\section{La individuación}

Gilbert Simondon (2009) basa su teoría de la individuación del ser en la perspectiva de las estructuras y las operaciones, oponiéndose a las dos vías tradicionales para abordar al ser como individuo: el sustancialismo y el hilemorfismo, en las que, según Simondon, la realidad del ser ya estaría dada de antemano y generaría unos entes estáticos, además de desconocer el proceso mediante el cual ese ser deviene (ontogénesis) y se individúa en interrelación con su medio asociado, que sería propiamente el proceso de individuación que Simondon se propone estudiar. En sus palabras:

Una situación hilemórfica es una situación en la cual no hay más que forma y materia, por tanto dos niveles de realidad sin comunicación. La institución de esta 
comunicación entre niveles — con transformaciones energéticas — es el inicio de la individuación; supone la aparición de una singularidad, que se puede llamar información, sea viniendo de afuera, sea subyacente (Simondon, 2009, pp. 114-115).

Para Simondon (2009), la individuación consiste en un desfasamiento del ser, en la medida en que existe una energía potencial o carga preindividual que es susceptible de ser actualizada en los individuos. De este modo,

El devenir es una dimensión del ser que corresponde a una capacidad que tiene de desfasarse en relación consigo mismo, de resolver al desfasarse; el ser preindividual es el ser en el cual no existe fase; el ser en el seno del cual se consuma una individuación es aquel en el cual aparece una resolución por repartición del ser en fases, que es el devenir; el devenir no es un marco en el cual existe el ser; es dimensión del ser, modo de resolución de una incompatibilidad inicial rica en potenciales (Simondon, 2009, pp. 26-27).

Simondon (2009) estudia la individuación como un proceso transversal a los objetos físicos y a los seres vivientes, incluyendo a los seres humanos. Para Heredia (2012), "el individuo es la instancia a partir de la cual dos órdenes de magnitud dispares (micro y macro) se comunican —en el marco de una realidad de magnitud media asociada al individuo: el medio-”" (p. 54). La individuación implica, entonces, "el desfasamiento; el darse del ser por fases" (Vargas, 2014, p. 37). El desfasamiento es una forma de individuación en tanto en cuanto permite resolver las tensiones intrínsecas entre las fases en las que se distribuye el ser.

La operación fundamental de la cual se sirve el proceso de individuación en estos distintos niveles de la realidad es la transducción, la cual consiste en la propagación de una actividad o información a través de un campo específico, siempre con tendencia a la amplificación, permitiendo así que surjan nuevas estructuras más estables, que a su vez darán lugar a ulteriores transformaciones. De este modo, se mantiene en los individuos una cantidad de carga preindividual susceptible de ser desplegada en cada sistema específico. En este sentido, para Simondon (2014), "la operación es el complemento ontológico de la estructura y la estructura el complemento ontológico de la operación" (p. 470). Esta operación, como ya se dijo, permite la transformación de una 
estructura en otra, y la nueva estructura está investida, permeada, por la anterior, es decir, por los procesos de individuación anteriores.

En un nivel físico, Simondon $(2009,2014)$ analiza la operación de individuación mediante el ejemplo del ladrillo de arcilla. En este caso, tal operación funciona mediante presiones externas que se combinan con las propiedades intrínsecas del objeto o del material y con las contingencias del proceso para dar lugar a un equilibrio relativo, que Simondon llama metaestabilidad. La metaestabilidad hace referencia a la existencia de grados de estabilidad en los sistemas abiertos, lo que implica que no existe el individuo completamente terminado y sin tensiones por resolver. En ese sentido, "un sistema contiene energía potencial cuando no está en su estado de mayor equilibrio" (Simondon, 2009, p. 96). De esta forma, en la individuación acontecen equilibrios metaestables sucesivos, en un sistema que está compuesto por el individuo y el medio del cual surge este. Es por lo anterior que el individuo es a la vez resultado parcial y agente de individuación (Bardin, 2015).

En los seres vivientes, cada proceso de individuación previo sirve de principio o apoyo para el siguiente, y este proceso de adaptación les permite crecer y desarrollarse dentro de su medio (Builes, 2017; Henao, 2016). "El ser viviente, luego de haber sido iniciado, continúa individuándose él mismo; es a la vez sistema individuante y resultado parcial de individuación" (Simondon, 2009, pp. 62-63). En este punto, Simondon (2009) plantea que

Lo viviente resuelve problemas, no solamente adaptándose, es decir modificando su relación con el medio (como puede hacer una máquina), sino también modificándose él mismo, inventando nuevas estructuras internas, introduciéndose él mismo completamente en la axiomática de los problemas vitales. El individuo viviente es sistema de individuación, sistema individuante y sistema individuándose; la resonancia interna y la traducción de la relación consigo mismo en información están en este sistema de lo viviente (p. 31).

De acuerdo con Builes (2017), Simondon critica la noción de adaptación, pues considera que en ella se presuponen al individuo y al medio como dos realidades separadas y estáticas, de modo tal que una se impone sobre la otra para alcanzar un equilibrio completo. No obstante, la adaptación es un proceso constante de intermodificación e interacción entre individuo y medio, en 
donde el primero actúa de forma activa frente al segundo, tal y como plantea Piaget (1999). Además, la adaptación es la operación específica de la cual se sirve la transducción en los niveles biológico y psíquico-transindividual (Builes, 2017); es correlativa al proceso de individuación y permite que se instituyan normas provisionales o equilibrios metaestables que posibilitan el funcionamiento de los individuos y de su entorno asociado. En este sentido, la adaptación (psicológica) no es opuesta a la invención, sino que es una invención en sí misma, que puede darse como una modificación de los esquemas propios y, a la vez, como una transformación e incorporación de objetos externos (Piaget, 1999).

Simondon (2013) plantea que la invención es el proceso final del ciclo de devenir de las imágenes, a las cuales otorga gran importancia, ya que las entiende como cuasiorganismos que habitan al individuo y le permiten resolver situaciones de tensión. El ciclo de las imágenes va desde una primera fase de anticipación de los objetos, pasando por el encuentro con los mismos por medio de contenidos y procesos afectivos y perceptivos; cuando estas imágenes devienen en símbolos, integrando estos dos tipos de contenidos, pueden dar lugar a la invención. $\mathrm{Al}$ respecto, Simondon (2013) menciona que

La imagen mental es como un subconjunto relativamente independiente al interior del ser viviente sujeto; en su nacimiento, la imagen es un haz de tendencias motrices, anticipación a largo plazo de la experiencia del objeto; en el curso de la interacción entre el organismo y el medio, se convierte en sistema de recolección de las señales incidentes y permite a la actividad perceptivo-motriz ejercerse según un modo progresivo. Finalmente, cuando el sujeto es separado nuevamente del objeto, la imagen enriquecida con aportes cognitivos e integrando la resonancia afecto-emotiva de la experiencia, se convierte en símbolo. Del universo de símbolos interiormente organizado que tiende a la saturación, puede surgir la invención que es la puesta en funcionamiento de un sistema dimensional más potente, capaz de integrar más imágenes completas según el modo de la compatibilidad sinérgica. Tras la invención, cuarta fase del devenir de las imágenes, el ciclo recomienza por una nueva anticipación del encuentro con el objeto, que puede ser su producción (pp. 9-10).

Para Simondon (2013), la invención da lugar a modos colectivos de expresión (como, por ejemplo, la ciencia), por medio de un descubrimiento de 
compatibilidad entre modos de existencia que no tenían sentido en estructuras precedentes. De esta forma, los objetos producidos por el hombre son $o b$ jetos imágenes, en la medida en que son portadores de significaciones latentes cognitivas, conativas y afectivo-emotivas que pueden desarrollarse en otros sujetos y en nuevas invenciones.

Los seres vivientes llevan a cabo los procesos de transducción (adaptación) mediante los diferentes sistemas que existen en ellos, es decir, mediante las funciones afectivo-emotivas y las funciones perceptivo-activas. Para Heredia (2012), "los sistemas vivos implican neguentropía, es decir, conjuran la entropía de su sistema incorporando energía del exterior y reproduciendo un orden metaestable que es condición de vida” (p. 61).

De acuerdo con lo dicho, consideramos que la transducción puede entenderse, al menos en parte, como una traducción. Traducir quiere decir 'interpretar', y el término proviene del latín tradud冈re, que quiere decir 'hacer pasar de un lugar a otro' (RAE, 2017). La transducción se realiza, entonces, entre los distintos niveles de la realidad, ya sea dentro de los mismos sistemas físicos o vivientes, o a través de dos niveles (por ejemplo, lo psíquico y lo transindividual). Como ejemplo de lo anterior, Ramírez (2011) plantea que "el sistema neurológico traduce las impresiones, las sensaciones y las tendencias en los términos de sus redes y sus reglas" (p. 1).

En el caso del ser humano, este puede participar activamente, como sujeto, de sus procesos de individuación, en interdependencia con su entorno, en una experiencia transindividual o psicosocial, que pone a los individuos en relación. "La categoría sujeto, en la teoría de Simondon, excede al individuo y solo se despliega como experiencia colectiva a través del potencial no realizado en cada singularidad" (Vargas \& Gil, 2015, p. 72). Para Stiegler (2012), "la metaestabilidad da cuenta de la individuación psicosocial como diferimiento de una identidad individual nunca plenamente constituida” (p. 137).

Pero el sujeto no puede desplegar por sí solo y en sí mismo su carga de realidad preindividual, y encuentra en otros la posibilidad de hacer surgir estructuras y funciones que antes no podían producirse. De este modo, la individuación psíquica es, a su vez, transindividual. Simondon (2009) describe lo transindividual como "aquello que está tanto en el exterior del individuo 
como dentro suyo; de hecho, lo transindividual, al no estar estructurado, atraviesa el individuo" (p. 453).

Lo colectivo es un nivel de individuación que permite la articulación del potencial presente en los sujetos y también entre ellos; este entre es reserva de información, a modo de una red que excede a los individuos. Para Simondon (2014), un individuo maduro es quien participa de lo colectivo y, además, lo construye, favoreciendo así el entre de los individuos, y permite generar significación.

\section{La epistemología genética}

Jean Piaget (1975), por su parte, se interesa en proporcionar una explicación sobre las operaciones presentes en la inteligencia humana, con base en su planteamiento acerca de la relación existente entre las realidades biológica y lógica. De este modo, este autor considera que existe una continuidad entre las distintas estructuras humanas, desde las más elementales hasta las más abstractas, y que estas atraviesan equilibrios cada vez más estables. De acuerdo con Piaget (1975), "la psicología operatoria será entonces, esencialmente, una teoría de las formas de equilibrio y de los pasajes de una forma a otra” (p. 142). Y

Entonces el universo no es conocido por el hombre más que a través de la lógica de las matemáticas, producto de su espíritu, pero no puede comprender cómo ha construido las matemáticas y la lógica si no se estudia a sí mismo psicológica y biológicamente, es decir, en función del universo entero (Piaget, 1972, p. 110).

Piaget (2002) considera que existen dos factores funcionales principales comunes a toda explicación psicológica sobre los comportamientos, estos son: la asimilación "o proceso según el cual una conducta se reproduce activamente y se integran nuevos objetos" (p. 56); y la acomodación, que consiste en la modificación de los propios esquemas de acuerdo con la diversidad de los objetos asimilados. Ambas funciones constituyen el proceso de adaptación, que, según hemos dicho, es la operación específica de la cual se sirve la transducción para generar modificaciones en las estructuras en los seres vivientes. 
Ahora bien, Piaget (1972), en su propuesta de una epistemología genética, plantea la importancia de comprender el conocimiento a partir de sus procesos genéticos, y, además, resalta que se han de comprender las estructuras cognitivas en términos de sus transformaciones. Por tanto, la definición de conocimiento se acerca más a un proceso que a un hecho ya dado o un estado.

La epistemología genética implica procesos biológicos, psicológicos y también lógicos; y, como su nombre, lo indica, requiere un proceso gradual de desarrollo en el ser humano. Como ejemplos de esto, Piaget (1972) plantea que entre los cuatro y los siete años se da una sucesión en la adquisición de conocimientos y habilidades: el infante humano, en primer lugar, se vuelve capaz de hacer seriaciones, es decir, de establecer relaciones de orden (primero A, luego B, etc.); y, en segundo lugar, forma agrupaciones o clases (A y A', B y B', etc.). También, con relación a la percepción, se da un predominio inicial de relaciones topológicas (de vecindad, continuidad, cierre, posiciones en relación con las fronteras, etc.), y solo posteriormente se comprenden las relaciones entre segmentos o figuras separadas, a partir de la interiorización de las nociones de espacialidad, según la geométrica y la métrica. Así,

La teoría del conocimiento es, pues, esencialmente una teoría de la adaptación del pensamiento a la realidad, aunque esta adaptación revelara finalmente, como sucede con todas las adaptaciones, la existencia de una interacción inextricable entre el sujeto y los objetos. Por consiguiente, considerar la epistemología como una anatomía comparada de las operaciones del pensamiento y como una teoría de la evolución intelectual o de la adaptación del espíritu a lo real no es disminuir para nada la importancia de su objetivo (Piaget, 1972, p. 28).

Ahora, es conocido que, según la tradición filosófica empirista, todo conocimiento proviene necesariamente de la experiencia. Sin embargo, para Piaget (1972), aunque esta brinda claramente unas bases para el conocimiento de los objetos del mundo, pues es la que permite descubrir las propiedades físicas de los mismos, existen también nociones abstractas que se van desarrollando en el infante a partir de la experiencia, o, más específicamente, a partir de las acciones que el infante realiza sobre los objetos; este va abstrayendo propiedades que conllevan la comprensión de unas operaciones y formas de coordinación más allá del objeto mismo. La reversibilidad expresa una transformación de 
las acciones en operaciones: hasta ese momento del desarrollo el pensamiento se había orientado hacia un fin y se refería a acciones inmediatas. "Las operaciones son, por el contrario, acciones coordinadas en sistemas reversibles tales que cada operación corresponde a una operación inversa posible que la anula" (Piaget, 1972, p. 38).

Teniendo en cuenta estos aspectos generales sobre la teoría de la individuación de Simondon y la epistemología genética de Piaget, en el siguiente apartado analizamos el argumento del isomorfismo de la teoría de la Gestalt.

\section{El isomorfismo, a la luz de la teoría de la individuación y la epistemología genética}

En matemática, el isomorfismo hace alusión a una "correspondencia biunívoca entre dos estructuras algebraicas que conserva las operaciones"; y, en geología, se llama isomorfos a "dos o más cuerpos: que, con diferente composición química, presentan igual estructura cristalina y pueden cristalizar asociados" (RAE, 2017). En este sentido, el isomorfismo implica una correspondencia entre dos términos o estructuras, sin que necesariamente sean iguales; es decir, no hay una relación de identidad entre ellos. De acuerdo con Ferrater Mora (1971), en la filosofía escolástica se consideraba que los entes lógicos tenían su fundamento en la realidad, pero no en el sentido de referirse a la realidad de un modo directo, sino que los entes lógicos podían entenderse a modo de un "mapa" que representa de forma isomorfa las estructuras fundamentales de lo real.

Desde la perspectiva de la teoría de la Gestalt en psicología, se retoma el concepto isomorfismo (iso: 'igual'; morphé: 'forma') y se plantea que este "[...] designa la correspondencia uno a uno entre los elementos de dos sistemas o conjuntos, por lo que resulta que también se corresponden las operaciones y relaciones de esos sistemas" (Mitri, 2002, p. 12).

La teoría de la Gestalt utiliza este concepto para indicar que existen correlaciones dinámicas entre los distintos niveles de la realidad (físico, biológico 
y psicológico) y para resaltar la interdependencia entre estos. Así, los procesos físicos, somáticos y mentales correspondientes a un mismo fenómeno, más allá de su diferencia en cuanto a sus dominios y a los elementos heterogéneos, poseerían una estructura funcional semejante entre sí.

[...] Su organización [de la forma o Gestalt] se da siguiendo los mismos principios y leyes en cada uno de ellos. Así los principios de configuración del movimiento de átomos y moléculas del cerebro y sus estados funcionales serían dinámica y funcionalmente semejantes a los de los sentimientos y pensamientos. Sus correspondencias estarían dadas por las propiedades estructurales esenciales y comunes a los tres ámbitos, y a la intelección de estas propiedades estructurales comunes apuntan los principios y leyes de la Gestalt (Mitri, 2002, p. 12).

El principio de isomorfismo está asociado con dos aspiraciones principales: 1) ir más allá de los postulados del monismo materialista y del dualismo, reconociendo que existen facetas distintas de la realidad, las cuales funcionan según relaciones y principios de organización estructural semejantes y comunes. "Así, lo real resulta diverso y continuo, por efecto de estar estructurado isomórficamente" (Mitri, 2002, p. 13); y 2) la comprensión del universo como dotado de ciertas determinaciones, como orden y sentido susceptible de ser explicado "en función de participar de las mismas leyes de organización estructural desde el movimiento de los átomos, pasando por la organización de lo vivo, hasta la lógica del pensamiento y la moral” (Mitri, 2002, p. 13).

Por su parte, Piaget (1978), aunque está de acuerdo con el argumento del isomorfismo como lo plantea la teoría de la Gestalt, sugiere que habría que profundizar en la idea de forma o estructura de la que se parte. Para él, estos niveles de la realidad o formas que analiza la teoría de la Gestalt no han de ser comprendidos como realidades o entidades estáticas o inmutables, sino que las estructuras de la realidad han de ser examinadas a partir de sus procesos genéticos y de desarrollo. De este modo, Piaget (1978) comprende el argumento del isomorfismo teniendo en cuenta las estructuras y las funciones dentro de ellas, es decir, considerando la posibilidad de transformación de las distintas realidades. En este sentido, explica: 
En una primera aproximación, una estructura es un sistema de transformaciones, que, como tal, está compuesto de leyes (por oposición a las propiedades de sus elementos), y que conserva o enriquece por el juego mismo de sus transformaciones, sin que éstas examinen fuera de sus fronteras o recurran a elementos exógenos. En resumen, una estructura comprende tres características: totalidad, transformaciones y autorregulación (Piaget, 2002, p. 6).

Según lo anterior, toda estructura parte y es el resultado de una génesis, que consiste en el paso de una estructura más simple a una más compleja, mediante una serie de relaciones entre elementos y transformaciones.

Piaget (1978) se basa, además, en el argumento del círculo de las ciencias, que plantea que incluso las ciencias más abstractas y formales, como la matemática y la lógica, están fundamentadas en la experiencia y en el pensamiento humano, del cual se ocupa la psicología; y que todas las ciencias poseen un devenir genético, como plantea el punto de vista histórico. Sobre este punto, amplía Piaget (1978):

Este círculo, por más real que sea, no por ello es un círculo vicioso o, al menos, son las cosas mismas que lo imponen. En efecto, sólo constituye un caso particular del círculo del sujeto y el objeto, círculo inevitable no sólo para todo conocimiento, sino incluso para toda teoría del conocimiento. El conocimiento se apoya en un objeto fuera del cual no sería afectado el sujeto (desde el interior o desde el exterior) y, por lo tanto, este sujeto no podría conocerse a sí mismo puesto que carece de toda actividad; pero este objeto sólo puede conocerse a través del sujeto, si no, sería inexistente para él (p. 54).

\section{Y más adelante agrega:}

Vemos pues que este círculo genético traduce precisamente el círculo constituido por la filiación efectiva de las categorías del pensamiento científico: las explicaciones de la psicología se refieren, tarde o temprano, a las de la biología; éstas se apoyan a su vez en las de la físico-química; las explicaciones físicas se apoyan en la matemática, y la matemática y la lógica sólo pueden fundarse en las leyes del espíritu que son el objeto de la psicología (Piaget, 1978, pp. 55-56).

Piaget (1978) considera, entonces, que existe un isomorfismo entre las estructuras mentales lógicas y algunas estructuras orgánicas: por ejemplo, la implicación lógica está estructurada de forma isomorfa a la causalidad en las 
acciones orgánicas. A este isomorfismo entre las estructuras lógicas y orgánicas, Piaget (1975) lo llama principio de paralelismo, y lo explica así:

En forma general, el paralelismo psicofisiológico es insostenible si se lo concibe como puesta en correspondencia de dos series causales autónomas; sin embargo, deja de serlo a partir del momento en que se concibe a la serie fisiológica como única causal y a la serie consciente como implicatoria, es decir como una construcción de relaciones que se determinan unas a otras en diversos grados. Considerado de este modo, el paralelismo hace de la conciencia una traducción de la serie orgánica, traducción incompleta ya que conserva sólo algunos pasajes, pero que proporciona una nueva interpretación sobre éstos, al ańadir al simple mecanismo causal el valor y la comprensión. Entonces, la conciencia, que crea vínculos de implicación entre los valores sentidos y entre las relaciones percibidas o concebidas, mantiene con las conexiones fisiológicas correspondientes una relación análoga a la que una relación lógica o matemática comporta en relación con el hecho físico que expresa: en ambos casos, existe una traducción más o menos completa, pero que enriquece al texto traducido al transponerlo al plano de los encadenamientos implicativos (p. 152).

De este modo, el argumento del isomorfismo es sustentado por la propuesta del círculo de las ciencias, en el sentido de que la lógica (o también la matemática), como ciencia formal, puede entenderse como una axiomatización de hechos presentes en lo mental, y estos hechos comportan, y hasta cierto punto provienen, de una dimensión psicofisiológica y, al fin y al cabo, biológica.

Además, según Piaget (2000), el isomorfismo no implica una relación estricta de término a término exacto entre las estructuras, sino que pueden darse grados de correspondencia o isomorfismo parcial, ya sea entre las estructuras o entre las operaciones de los distintos niveles de la realidad. Y aún se podría hablar de isomorfismo si se cumplen las siguientes dos condiciones:

- Que exista la posibilidad de indicar un proceso de transformación desde una de las estructuras comparadas hacia la otra;

- Que este proceso de transformación pueda darse de forma real y que en él pueda identificarse un devenir histórico y genético.

Como ejemplo de lo anterior, Piaget (2000) plantea una estructura que son las relaciones de orden que se dan en todos los niveles orgánicos: los genes 
están ordenados espacialmente en espirales de ADN e intervienen según un orden temporal en el desarrollo epigenético. También hay orden de sucesión en el funcionamiento fisiológico que va, por ejemplo, desde un reflejo simple, hasta el desarrollo de un instinto complejo. En el campo conductual y de aprendizaje intervienen relaciones de orden cuando existen medios sucesivos que se emplean para alcanzar un objetivo. Y en las operaciones intelectuales, un niño en cierto momento es capaz de realizar una seriación de objetos por relaciones de orden a partir de sus percepciones sobre los objetos.

En una vía que consideramos similar, Simondon (2009) parte de una crítica tanto al asociacionismo como a la teoría de la Gestalt, ya que plantea que

Existe una génesis de las formas como existe una génesis de la vida. El estado de entelequia no está enteramente determinado por el haz de virtualidades que lo preceden y lo preforman. Lo que falta tanto al asociacionismo como a la teoría de la forma es un estudio riguroso de la individuación, es decir de ese momento crítico en el que aparecen la unidad y la coherencia (p. 347).

Según lo anterior, Simondon critica tanto al asociacionismo como a la teoría de la Gestalt por desconocer la importancia del estudio del proceso genético y de transformación de lo diverso en una forma determinada. Para Simondon, este proceso de transformación e invención de una forma se da gracias a la percepción; de modo que la percepción no es una captación pasiva de una forma estática, sino el descubrimiento de una compatibilidad, la resolución de una disparidad intrínseca, que nos permite percibir los objetos como estables a pesar de su constante cambio; en ese sentido, es la invención de una forma que implica relación activa entre sujeto y objeto y una intermodificación. "[La forma] es susceptible de degradarse, como todas las formas físicas y vitales, y esta degradación es también una degradación de la totalidad del sujeto, pues cada forma es parte de la estructura del sujeto" (Simondon, 2009, p. 349). De acuerdo con lo dicho,

Creer que él [el sujeto] capta de una vez formas completamente constituidas es creer que la percepción es un puro conocimiento y que las formas están enteramente contenidas en lo real; de hecho se instituye una relación recurrente entre el sujeto y el mundo el cual debe percibir. Percibir es atravesar; sin ese gesto activo que 
supone que el sujeto forma parte del sistema en el cual se plantea el problema perceptivo, la percepción no podría llevarse a cabo (Simondon, 2009, pp. 362-363).

En este sentido, consideramos que Simondon (2009) está de acuerdo con Piaget en que la estructura es relación, transformación y operación, y ha de entenderse mediante un proceso genético y no como un ente estático e inmutable. En este sentido, Simondon (2014) plantea que

En lugar de concebir una forma arquetípica que domina la totalidad, e irradia por encima de ella, como el arquetipo platónico, ¿no podríamos plantear la posibilidad de una propagación transductiva de la adquisición de la forma, que avanza etapa por etapa, al interior del campo? (p. 507).

Ahora bien, además de estar de acuerdo con Piaget en este punto, también consideramos que es posible leer el argumento del isomorfismo desde una mirada simondoniana, ya que en todos los niveles del ser que plantea, aunque hay características y procesos diversos en complejidad, se conserva la operación fundamental de transducción.

Con base en lo anterior, nos preguntamos: ¿đe qué se sirve la operación transductiva para efectivamente producir transformaciones y generar amplificación en las estructuras o formas? Y respondemos, con Simondon (2014), que la transducción se sirve de la información:

La teoría de la información es el punto de partida de un conjunto de investigaciones que han fundado la noción de entropía negativa (o neguentropía), que muestra que la información corresponde a lo inverso de los procesos de degradación y que, al interior del esquema completo, la información no es definible a partir de un único término, como la fuente, o como el receptor, sino a partir de la relación entre fuente y receptor (p. 497).

En ese sentido, la operación de transformación en un sistema, que podríamos llamar información, está presente en todos los niveles de la realidad, aunque se exprese y genere resultados diferentes en cada uno de ellos. Para Builes (2017) la definición clásica de información agrupa el control de los sistemas biológicos, mecánicos y artificiales; y en este sentido, ubica al hombre, los animales y las máquinas en un mismo nivel. 
No obstante lo anterior, no habría que entender la información en términos de las concepciones clásicas de la teoría de la comunicación, es decir, como una cantidad cuantificable que se transmite sin modificaciones y que es recibida de forma pasiva por el receptor; más bien, habría que tener en cuenta la dimensión activa por parte del receptor y la carga de indeterminación presente en la misma información (Builes, 2017). Además, se ha de considerar el nivel de complejidad de cada uno de los niveles de la realidad y las particularidades que cada uno agrega con respecto al anterior, como se planteó anteriormente en el ejemplo de isomorfismo para Piaget. Sobre esta noción de información, Simondon (2016) aclara que

\begin{abstract}
Ser o no ser información no depende solamente de los caracteres internos de una estructura; la información no es una cosa, sino la operación de una cosa que llega a un sistema y que produce allí una transformación. La información no puede definirse más allá de este acto de incidencia transformadora y de la operación de recepción. No es el emisor el que hace que una estructura sea información, puesto que una estructura puede comportarse como información por relación a un receptor dado sin haber sido compuesto por un emisor individualizado y organizado; algunos impulsos provenientes de un fenómeno de azar pueden activar un receptor determinado tan bien como si provinieran de un emisor (p. 139).
\end{abstract}

Lo anteriormente planteado acerca de la lectura del isomorfismo en Simondon puede ejemplificarse mediante el llamado lenguaje de máquina o lenguaje de programación de computadores. Para Ramírez (1980), "un programa es un conjunto de instrucciones y datos que suministra el usuario al computador para realizar un proceso o resolver un problema. El 'Compilador' transforma estas instrucciones en 'Instrucciones de máquina”' (p. 19). El lenguaje de máquina consiste entonces en proveer instrucciones a un sistema, basadas en una lógica binaria y un conjunto de datos determinados. Pero estas son solamente el primer eslabón de un proceso o resolución de un problema que toma en cuenta estas instrucciones a modo de información y las toma como base para producir futuras transformaciones dentro de ese sistema; asimismo, se puede generar posteriormente una secuencia de acciones por parte de la máquina frente a un problema al que se enfrente. 
Consideramos que este proceso de traducción de información sucede de forma isomorfa en las estructuras biológicas y psicológicas. En este sentido, Freud (1992) se pregunta en qué consisten las fallas lógicas en el pensamiento, y responde:

Dicho brevemente: en no tomar en cuenta las reglas biológicas para el decurso de pensar. Estas reglas enuncian adónde tiene que dirigirse en cada caso la investidura-atención y cuándo es preciso detener el proceso de pensar. Tales reglas están protegidas por amenazas de displacer, son obtenidas por la experiencia, y se pueden trasponer sin más a las reglas de la lógica, cosa que será menester probar en detalle. El displacer intelectual de la contradicción, a raíz de la cual el decurso de pensar examinador se detiene, no es entonces más que el [displacer] almacenado para proteger las reglas biológicas, que el proceso de pensar incorrecto pone en movimiento. La existencia de tales reglas biológicas se demuestra, justamente, a partir del sentimiento de displacer por fallas lógicas (p. 435).

Así, también Freud (1992) asimila las reglas biológicas a reglas lógicas, y según lo dicho, podríamos plantear que son isomorfas. Para Ramírez (2011),

Sin embargo, hay que tener en cuenta que el sistema neurológico traduce las impresiones, las sensaciones y las tendencias en los términos de sus redes y reglas. Aunque Freud muy probablemente hubiera compartido la afirmación de Jean Piaget de que el sistema neurológico tiene la misma estructura de la realidad, pudo darse cuenta de los diversos registros que tiene el aparato psíquico, cada uno de ellos con lógicas diferentes (p. 1).

Resaltando el hecho de la relación existente entre los distintos niveles del ser y la gradualidad con la que ha de analizarse el proceso de individuación entre ellos, Simondon (2009) plantea la siguiente reflexión, que proponemos a modo de conclusión de lo dicho:

Postular que el sentido interior es también un sentido exterior, que no existen islotes perdidos en el devenir, ni regiones eternamente cerradas sobre sí mismas, ni autarquía absoluta del instante, es afirmar que cada gesto posee un sentido de información y es simbólico en relación con la vida entera y con el conjunto de vidas (p. 498). 


\section{Conclusiones}

Para concluir, podríamos decir lo siguiente:

1. La teoría de la individuación del ser de Simondon parte del estudio de la dialéctica entre lo que cambia y lo que permanece, y entiende al ser como relación, más que como entidades o términos predeterminados e inmutables. Este autor propone la individuación como un proceso transversal a los objetos físicos y a los seres vivientes, incluyendo allí a los seres humanos (individual y transindividualmente). La operación fundamental de la cual se sirve la individuación para resolver las tensiones es la transducción, que permite que se den modificaciones en una estructura a partir de una propagación de información (que implica una traducción) y de una tendencia del ser a la amplificación.

2. Jean Piaget parte del estudio de la inteligencia y propone que todo el conocimiento ha de entenderse a partir de sus procesos genéticos, y plantea que existe una continuidad entre las estructuras biológicas y las estructuras lógicas, las cuales atraviesan por fases de equilibrios sucesivos.

3. El concepto de isomorfismo entendido como correspondencia término a término entre dos estructuras ha sido retomado por la psicología de la Gestalt en cuanto a los distintos niveles de la realidad; no obstante, isomorfismo no quiere decir relación de identidad. Más bien, para Piaget, hay grados de correspondencia entre las estructuras o las operaciones presentes en cada nivel de la realidad, y hay que tener en cuenta el nivel de complejidad de cada una de las estructuras, como en el caso de la causalidad biológica que es isomorfa a la implicación lógica. Finalmente, planteamos una lectura de este argumento del isomorfismo desde la perspectiva simondoniana, pues consideramos que la operación de transducción que se da por medio de la información y la traducción se mantiene en todos los niveles de la realidad, aunque los resultados que genera varían en sus procesos y en su grado de complejidad. Consideramos entonces que es posible entender el concepto de isomorfismo tanto desde Piaget como desde Simondon. Ambos tienen en cuenta que existe 
una continuidad entre las distintas estructuras y operaciones presentes en los distintos niveles de la realidad, y que puede haber correspondencia entre las mismas.

4. Aceptar el isomorfismo entre distintos niveles de la realidad, no implica la negación de la posibilidad de invención, pues la información dentro de un sistema que permite que se den modificaciones en el mismo no es un asunto predeterminado ni predecible en sus resultados, sino que, más bien, en el proceso de individuación hay una relación dialéctica constante entre lo intrínseco de un sistema, lo extrínseco y lo aleatorio. 


\section{REFERENCIAS}

Bardin, A. (2015). Epistemology and Political Philosophy in Gilbert Simondon. Individuation, Technics, Social Systems. Londres: Springer.

Builes, I. (2017). Sobre la noción de información y algunas implicaciones en el ámbito psicosocial. Revista Colombiana de Filosofía de la Ciencia, 17(34), 161-178.

Builes, I. (2018). Aspectos lógicos del pensamiento intuitivo y sus implicaciones en la toma de decisiones (Tesis de maestría). Universidad EAFIT, Medellín, Colombia.

Ferrater Mora, J. (1971). Diccionario de filosofía. Tomo I A-K. Buenos Aires: Sudamericana.

Freud, S. (1992). Proyecto de psicología. En Obras completas (Vol. 1). Buenos Aires: Amorrortu.

Henao, C. (2016). Mediación analítica organizacional. En H. Manrique, I. Lopera, J. Pérez, V. Ramírez y C. Henao, Clínica analitica de las organizaciones (pp. 177228). Bogotá: San Pablo.

Heredia, J. M. (2012). Los conceptos de afectividad y emoción en la filosofía de Gilbert Simondon. Revista de Humanidades 26, 51-75.

Mitri, J. O. (2002). Sobre la gestalttheorie. Posición y función de la psicología de la Gestalt en el pensamiento contemporáneo. En M. Lodieu \& H. Scaglia, (comps.), Construcciones en psicología (pp. 1-21). Buenos Aires: Proyecto Editorial.

Piaget, J. (1972). Psicología y epistemología. Buenos Aires: Emecé Editores.

Piaget, J. (1975). Introducción a la epistemología genética. El pensamiento biológico, psicológico y sociológico. Buenos Aires: Paidós. 
Piaget, J. (1978). Introducción a la epistemología genética. El pensamiento matemático. Buenos Aires: Paidós.

Piaget, J. (1999). La psicología de la inteligencia. Barcelona: Crítica.

Piaget, J. (2000). Biología y conocimiento. México: Siglo XXI.

Piaget, J. (2002). El estructuralismo. México: Cruz O.

Ramírez, C. A. (1980). Programación de computadores y calculadoras electrónicas. Medellín: Coopep.

Ramírez, C. A. (2011). Cav. 84. Contradicción. (Documento inédito). Texto policopiado por el grupo de investigación El método analítico. Medellín.

Real Academia Española (2017). Diccionario de la lengua española. Recuperado de http://dle.rae.es/?id=MCHU9xu

Simondon, G. (2009). La individuación. A la luz de las nociones de forma y de información. Buenos Aires: Cactus-La Cebra.

Simondon, G. (2013). Imaginación e invención. Buenos Aires: Cactus.

Simondon, G. (2014). La individuación a la luz de las nociones de forma y de información. $2^{\circ}$ ed. Buenos Aires: Cactus.

Simondon, G. (2016). Comunicación e información. Buenos Aires: Cactus.

Stiegler, B. (2012). Tiempo e individuaciones técnica, psíquica y colectiva en la obra de Simondon. Trilogia, (6), 133-146.

Vargas, G. (2014). Individuación y anarquía. Cali: Aula de Humanidades.

Vargas, G. y Gil, L. M. (2015). Excelencia, excedencia e individuación: el problema de la formación como despliegue de la tecnicidad. Revista Colombiana de Educación, 68, 65-90. 